\title{
EDITORIAL
}

\section{COLLABORATIVE EFFORTS TO PREVENT ALZHEIMER'S DISEASE}

\author{
J. TOUCHON ${ }^{1}$, J. ROSENBAUM ${ }^{2}$, P. AISEN ${ }^{3}$, S. ANDRIEU $4,5,6,7$, M.C. CARRILLO ${ }^{8}$, M. CECCALDI ${ }^{9}$, \\ J.-F. DARTIQUES ${ }^{10}$, H. FELDMAN ${ }^{11}$, A. GABELLE ${ }^{12}$, M. ISAAC $^{13, *}$, L.J. FITTEN $^{14}$, R.A. SPERLING ${ }^{15}$, \\ B. VELLAS ${ }^{4,5,6}$, P. TARIOT ${ }^{16}$, M. WEINER ${ }^{17}$
}

\begin{abstract}
1. Montpellier University, INSERM U 1061, Montepellier, France; 2. Office for Science and Technology, Consulate General of France in Los Angeles, CA, USA; 3. Alzheimer's Therapeutic Research Institute (ATRI), Keck School of Medicine, University of Southern California, San Diego, CA, USA; 4. UMR1027 Inserm, F-31073, Toulouse, France;

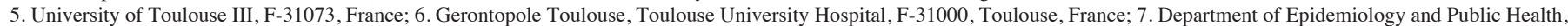

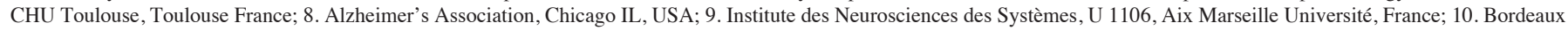

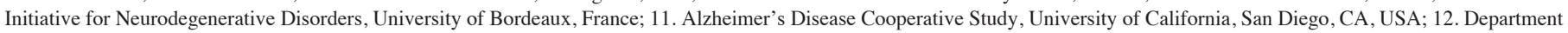

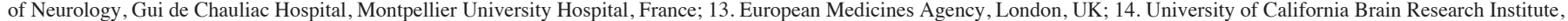

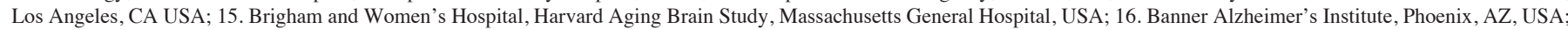

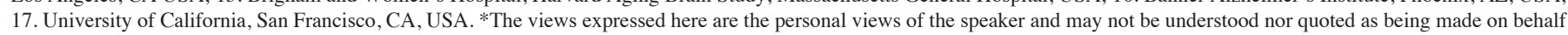
of or reflecting the position of EMA or any one of its committees or working parties or any of the national agencies. Corresponding author: Jacques Touchon, University Hospital of Montpellier, 34025 Montpellier Cedex 5, France, jacques.touchon@wanadoo.fr
\end{abstract}

Under the auspices of the Embassy of France in the United States and the Office for Science \& Technology at the General Consulate of Los Angeles, researchers from the US and France met on December 10, 2016, to discuss existing collaborative projects aimed at Alzheimer's disease (AD) prevention and explore the potential for future collaborations between Europe and the US. The symposium was the final session of the 2016 Clinical Trials in Alzheimer's Disease (CTAD) meeting in San Diego, California, USA. CTAD was created in 2008 as a forum to bring together an international group of AD experts and create a link between Southern Europe and the US, and has evolved to become one of the major international AD meetings, and the only one with a singular focus on treatment development. In the last five to seven years, prevention has become a major focus of AD treatment development (1).

\section{International collaborations to prevent Alzheimer's disease}

The Alzheimer's Disease Neuroimaging Initiative (ADNI) and the Australian Imaging Biomarkers and Lifestyle Study of Aging (AIBL) are among the most successful models of international collaboration. ADNI evolved from a US- and Canada-based clinical research study aimed at identifying and validating preclinical and prodromal biomarkers of AD to the pre-eminent multinational research program supporting advances in treatment and prevention. ADNI data have been instrumental in demonstrating that the disease begins decades before symptoms appear and progresses relentlessly toward dementia (2). These studies provided the rationale for preventive approaches that begin treatment in the earliest, preclinical stages of disease. Now, biomarker and cognitive endpoint data from ADNI are being used to design large multinational prevention trials that will identify those at risk for developing disease and institute treatments targeting the earliest steps in disease pathogenesis $(3,4)$.

The Multi-domain Alzheimer's Prevention Trial (MAPT), which began in Toulouse, France and was later expanded throughout France, also provides a potentially replicable model of collaboration. An early MAPT pilot study observed a slowing of cognitive decline in older adults who received an intervention approach combining nutritional counseling, exercise, and cognitive and social stimulation with omega-3 fatty acid supplementation (5). The MAPT model is now being expanded to include new studies, including e-MAPT, which uses an internet-based-platform for multi-domain intervention and cognitive monitoring; Low-MAPT, which targets older adults with low DHA/EPA in red blood cells in a double blind randomized controlled trial (RCT); and the Nolan Trial, which will target older adults with memory complaints in a 4-year double blind RCT, testing a Brain Protector Blend versus placebo. This MAPT research program involved both primary care and specialty dementia research clinics.

Another multidomain intervention study at the forefront of international efforts to develop effective interventions for $\mathrm{AD}$ is the Finnish Geriatric Intervention Study to Prevent Cognitive Impairment and Disability (FINGER), which combines nutritional guidance, exercise, cognitive training, social activities, and management of metabolic and vascular risk factors (6).

The involvement of regulatory agencies has been and will continue to be key to these collaborative efforts. In recent years, the European Medicines Agency (EMA) and the US Food and Drug Administration (FDA) have begun to work more closely to align regulatory pathways. The EMA published a draft guideline in 2016 on the development of AD treatments for early stage disease (7) that parallels the FDA draft guidance published in 2013 (8), although with some differences resulting from the evolving knowledge about $\mathrm{AD}$ biomarkers and other types of assessments. Both agencies also both endorsed a datadriven model of disease progression as a tool to increase the efficiency of clinical trials $(9,10)$. 
THE JOURNAL OF NUTRITION, HEALTH \& AGING@

Table 1

Current AD Prevention Trials

\begin{tabular}{|c|c|c|c|c|}
\hline Trial & Target Population & Treatment & Primary Endpoint & Duration of trial \\
\hline DIAN-TU & Individuals with autosomal dominant mutations & Gantanerumab, & & \\
\hline \multirow[t]{2}{*}{ Solanezumab } & Cognitive composite & & & \\
\hline & 4 years of treatment & & & \\
\hline A4 & Amyloid-positive individuals & Solanezumab & Cognitive Composite & 3 years \\
\hline API-ADAD & Kindred with autosomal dominant mutations & Crenezumab & Cognitive composite & 5 years \\
\hline API Generation & APOE4 homozygotes & $\mathrm{A} \beta$ immunotherapy & & \\
\hline BACE1 inhibitor & $\begin{array}{l}\text { Dual: cognitive composite plus delay in onset of } \\
\text { MCI or AD }\end{array}$ & 5 years & & \\
\hline TOMMORROW & At-risk & Pioglitazone & $\begin{array}{l}\text { Delay in onset of MCI or } \\
\mathrm{AD}\end{array}$ & 5 years \\
\hline MAPT & Frail older adults & Multidomain intervention & Cognitive composite & $\begin{array}{l}3 \text { years of treatment plus } 2 \\
\text { years observation }\end{array}$ \\
\hline FINGER & Subjects at risk to develop dementia & Multidomain intervention & $\begin{array}{l}\text { Neuropsychological Test } \\
\text { Battery }\end{array}$ & $\begin{array}{l}2 \text { years of treatment plus } 5 \\
\text { years observation }\end{array}$ \\
\hline
\end{tabular}

\section{The challenges ahead}

Prevention trials face multiple challenges due to the high degree of heterogeneity in the rates of progression towards dementia, the lack of sensitive measures to detect decline or a slowing of decline in the early stages of disease, and inadequate clinical trials infrastructure to identify, recruit, and retain sufficient numbers of participants to carry out long duration and lengthy trials (11-13). Identifying the appropriate study participants and defining the critical window for preventing $\mathrm{AD}$ and has also proved difficult, particularly since different treatments that target different pathological manifestations of the disease may have different critical windows. A major limitation is that studies done on research cohorts or in specific geographical areas may not be generalizable to the entire population. In addition, patients and caregivers may be reluctant to join prevention studies in the absence of a proven treatment that slows progression of the disease.

Nonetheless, the impact of AD on individuals, families, the public health, and the financial health of governments worldwide demands and international collaborative response. In France, the cost of $\mathrm{AD}$ exceeds $€ 20$ billion per year in formal and informal care. In the US, the cost has been estimated at $\$ 225$ billion per year and is expected to rise to $\$ 1$ trillion by 2050 (14).

Participants at the symposium identified several factors that could maximize the potential of global efforts to move towards prevention, including:

- Increased alignment between FDA, EMA, and industry sponsors on the use of biomarkers and cognitive measures in prevention studies.

- Replication of the ADNI data sharing model across other international research initiatives and among industry partners.

- Development and deployment of consistent, accurate, and easily understandable public health messages about prevention opportunities.

- Creation of networks of trial sites with the capacity to conduct patient-centered prevention trials (15).

Funding: Supported by an educational grant from the Office of Science and Technology of the Consulate General of France in Los Angeles, CA, USA

\section{References}

1. Lin J, Dong B, Vellas B. Editorial: Preventive Trials for Alzheimer's Diseases: The Multi-domain and the Targeted Therapies Approaches Will Have to Be Associated. J Nutr Health Aging. 2016;20(5):494-5.

2. Weiner MW, Veitch DP, Aisen PS, Beckett LA, Cairns NJ, Cedarbaum J, et al. 2014 Update of the Alzheimer's Disease Neuroimaging Initiative: A review of papers published since its inception. Alzheimers Dement. 2015;11(6):e1-e120.

3. Insel PS, Donohue MC, Mackin RS, Aisen PS, Hansson O, Weiner MW, et al. Cognitive and functional changes associated with Abeta pathology and the progression to mild cognitive impairment. Neurobiol Aging. 2016;48:172-81.

4. Insel PS, Mattsson N, Mackin RS, Kornak J, Nosheny R, Tosun-Turgut D, et al Biomarkers and cognitive endpoints to optimize trials in Alzheimer's disease. Ann Clin Transl Neurol. 2015;2(5):534-47.

5. Vellas B, Carrie I, Gillette-Guyonnet S, Dartigues JF, Touchon J, Dantoine T, et al MAPT: A multidomain approach for preventing Alzheimer's disease: Design and baseline data. J Prev Alz Dis. 2014;1(1):13-22.

6. Kivipelto M, Solomon A, Ahtiluoto S, Ngandu T, Lehtisalo J, Antikainen R, et al. The Finnish Geriatric Intervention Study to Prevent Cognitive Impairment and Disability (FINGER): study design and progress. Alzheimers Dement. 2013;9(6):65765.

7. European Medicines Agency. Draft guideline on the clinical investigation of medicines for the treatment of Alzheimer's disease and other dementias. In: CHMP, editor. London, UK2016.

8. Food and Drug Administration. Draft Guidance for Industry. Alzheimer's disease: Developing drugs for the treatment of early stage disease. . Accessed 2-24-2013 at http://www.fda.gov/downloads/Drugs/GuidanceComplianceRegulatoryInformation/ Guidances/UCM338287.pdf; 2013.

9. European Medicines Agency. Qualification opinion of a novel data driven model of disease progression and dtrial evaluation in mild and moderate Alzheimer's disease. In: http://www.ema.europa.eu/docs/en_GB/document_library/Regulatory_and_ procedural_guideline/2013/10/WC500151309.pdf aoa, editor. 2013.

10. Food and Drug Administration. Regulatory letter to Critical Path Institute and CAMD 


\section{COLLABORATIVE EFFORTS TO PREVENT ALZHEIMER'S DISEASE}

regarding disease simulation tool. 2013.

11. Lista S, Dubois B, Hampel H. Paths to Alzheimer's disease prevention: from modifiable risk factors to biomarker enrichment strategies. J Nutr Health Aging. 2015;19(2):154-63.

12. Vellas B, Bateman R, Blennow K, Frisoni G, Johnson K, Katz R, et al. Endpoints for Pre-Dementia AD Trials: A Report from the EU/US/CTAD Task Force. J Prev Alzheimers Dis. 2015;2(2):128-35.
13. Petersen RC. Barriers for prevention and prodromal AD trials. J Prev Alz Dis. 2016;3(2):66-7.

14. Alzheimer's Association. Changing the trajectory of Alzheimer's disease. 2015.

15. Cummings J, Aisen P, Barton R, Bork J, Doody R, Dwyer J, et al. Re-engineering Alzheimer clinical trials: Global Alzheimer's Platform Network. J Prev Alz Dis. 2016;3(2):114-20. 